\title{
Simuleringsträning utvecklar lärarstudenters yrkesspecifika kunskaper
}

\author{
Anja Thorsten, Joakim Samuelsson och Marcus Samuelsson \\ Linköpings universitet, Sverige
}

\begin{abstract}
Syftet med denna artikel är att bidra med kunskap om hur lärarstudenters tilltro till den egna undervisningsförmågan kan utvecklas genom träning av undervisning med virtuella elever i en semivirtuell miljö som en del av en campusförlagd utbildning. Studien fokuserar på olika former av undervisning och vilken inverkan de kan ha för att utveckla studenters yrkesspecifika kunskaper. Utifrån Banduras teori om självtillit studerades två grupper av studenter som fick olika slags undervisning. Resultaten visar att studenterna som utöver ordinarie undervisning också fick coachad simuleringsträning ökade tilltron till sin förmåga att leda undervisningen i matematik signifikant mer än studenterna som enbart fick del av kursens teoridelar. En förklaring till skillnaden kan vara att träningen i sig erbjöd den ena gruppen studenter möjlighet till iscensättande upplevelser i anslutning till den campusförlagda utbildningen. Detta utöver den verksamhetsförlagda utbildningen som bägge grupperna fick del av. De studenterna fick på så sätt utöver att prata om undervisning också agera och vara $i$ undervisning. På så sätt sammankopplades den coachade simuleringsträningen till såväl yrkeskunnandets handlingsorienterade sida som dess analysorienterade sida. En annan förklaring kan ha att göra med att kombinationen av simuleringsträning och coachning också gav viktiga erfarenheter för de studenter som gjorde ställföreträdande erfarenheter genom att observera andras träning i simuleringsträningen.
\end{abstract}

Nyckelord: yrkeskunnande, lärarutbildning, simuleringsträning, professionsutveckling, didaktik

\section{INLEDNING}

Inom högre utbildning finns det flera slags yrkesutbildningar. Dessa utbildningar ska ge studenter en teoretisk såväl som en praktisk grund att stå på så de klarar sitt framtida yrke. Det finns en lång tradition av teorikurser på universiteten, men får studenter på yrkesprogram tillräckligt med stöd och träning i de praktiska yrkesfärdigheterna? På lärarprogrammen, liksom på andra yrkesförberedande program, används framför allt den verksamhetsförlagda utbildningen (VFU) för att ge studenterna praktisk träning i yrket. Flera forskare menar att den träning som sker på VFU inte räcker och att lärarstudenterna till följd av det får otillräckliga möjligheter att under utbildningen utveckla färdigheter och strategier för att hantera den komplexa klassrumsverkligheten (McDonald, Kazemi \& Schneider Kavanagh, 2013; Roofe \& Miller, 2013; Westbury, Hansén, Kansanen \& Björkvist, 2005; Lindqvist, Weurlander, Wernerson \& Thornberg, 2019). Den campusförlagda utbildningen (CFU) har stort fokus på teorier och stöttar utvecklingen av studenternas analytiska förmåga. Även om studenterna får goda kunskaper i relevanta teorier, så beskriver de att det är svårt att koppla innehållet från CFU till det praktiska utövandet av

*Författarkontakt: anja.thorsten@liu.se

Artiklar och reflektioner är kollegialt granskade. Övriga bidragstyper granskas av redaktionen. Se https://hogreutbildning.se ISSN 2000-7558

(C2021 Anja Thorsten, Joakim Samuelsson and Marcus Samuelsson. This is an Open Access article distributed under the terms of the Creative Commons Attribution-NonCommercial 4.0 International License (https://creativecommons.org/licenses/by-nc/4.0/), allowing third parties to share their work (copy, distribute, transmit) and to adapt it, under the condition that the authors are given credit, that the work is not used for commercial purposes, and that in the event of reuse or distribution, the terms of this license are made clear.

Citation: Thorsten, A., Samuelsson, J. \& Samuelsson, M. (2021). «Simuleringsträning utvecklar lärarstudenters yrkesspecifika kunskaper», Högre utbildning, 11(2), 21-36. http://dx.doi.org/10.23865/hu.v11.2702 
yrket (Lindqvist et al., 2019). Enligt Grossman, Hammerness och McDonald (2009) behöver lärarutbildningen hjälpa studenter att göra denna sammankoppling. De påtalar vidare att den praktiska träning studenterna får på sin VFU inte räcker och fortsatt att det finns ett behov av att i större utsträckning möjliggöra praktisk träning även under CFU. Genom riktad träning skulle ett specifikt yrkeskunnande kunna synliggöras. På så sätt kan yrkets analytiska sida och dess handlingsorienterade sida länkas samman (Anthony, Hunter \& Hunter, 20I5; Grossman et al., 2009; Uljens, 1997). En sådan sammanlänkning skulle kunna minska den "yrkeschock" som många nyexaminerade lärare upplever sig drabbade av när de börjar arbeta (se Fantilli \& McDougall, 2009; You \& Conely, 20I5). Ny teknik öppnar för nya möjligheter för en annan slags träning. Träning med simulerade elever i en semivirtuell miljö, i kombination med respons från studiekamrater och seminarielärare/experter, skulle kunna vara en möjlig väg för att bättre förbereda lärarstudenter inför sin VFU och för sitt framtida yrke (Bautista \& Boone, 20I5; Cohen, Wong, Krishnamachari \& Berlin, 2020). Två centrala förmågor inom läraryrket är undervisningskompetensen och ledarskapet (Granström, 2007). Tidigare studier har visat att lärares tilltro till sin egen undervisningsförmåga inom ett specifikt ämne är direkt kopplad till elevers prestationer i ämnet (Caprara, Barbaranelli, Steca \& Malone, 2006). I ljuset av ovanstående är syftet att studera utvecklingen av lärarstudenters tilltro till den egna förmågan att leda undervisning i matematik genom träning av undervisning $i$ en semivirtuell miljö i kombination med lärarledda reflekterande samtal. Följande forskningsfrågor besvaras:

I) Vilken effekt har coachad undervisningsträning i en semivirtuell miljö för lärarstudenters tilltro till sin egen förmåga att leda undervisning i matematik?

2) Hur utvecklas lärarstudenters tilltro till sin egen förmåga att leda undervisning i matematik under VFU, om de inför densamma tränat på undervisning i en coachad semivirtuell miljö?

\section{PRAKTISK YRKESTRÄNING I LÄRARUTBILDNINGEN}

Uljens (1997) beskriver att läraryrket har en analytisk sida och en handlingsorienterad sida. Dessa bägge sidor ska dock inte betraktas som separerade. I lärares yrkespraktik är de istället sammanvävda. Lärarutbildningen skulle kunna möta behovet av att sammankoppla dessa båda sidor genom att erbjuda lärarstudenter möjlighet att på CFU praktiskt träna på teoretiskt grundande lärarförmågor, med stöd av coachning från lärarutbildare. Genom träning i en kontrollerad miljö, som en simulering, kan studenterna ges möjlighet att utveckla avancerade förmågor som är svåra att utveckla och direkt bemästra i en autentisk, men komplex, klassrumsmiljö (Anthony et al., 20I5; Cohen et al., 2020; McDonald et al., 2013). Ett sätt att stötta lärarstudenternas utveckling av centrala lärarförmågor är, enligt Hattie (2009), så kallad mikroundervisning (microteaching). Vid mikroundervisning fokuserar man på ett avgränsat undervisningsinnehåll i korta undervisningssekvenser. Målsättningen är att studenterna ska få träna i en kontrollerad, trygg miljö och att de sedan ska få återkoppling på sin undervisning. Grossman (2005) påtalar att för att mikroundervisning ska vara framgångsrik är det viktigt att inte enbart ge återkoppling på det praktiska utövandet, utan att också koppla detta till teoretiska analyser och förklaringsmodeller. Genom sådana mikroanalyser blir det möjligt för studenten att få syn på avgörande aspekter av sin egen undervisning och hur det kan påverka elevers lärande (Anthony et al., 2015).

Mikroundervisningen har traditionellt skett främst antingen med verkliga elever eller genom att lärarstudenternas kamrater agerar elever (se t.ex. Anthony et al., 20I5; Hattie, 2009; Grossman et al., 2009). Det finns dock utmaningar med båda dessa varianter. Om studenterna enbart tränar 
undervisning med verkliga elever i ett verkligt klassrum kan det innebära att mer avancerade lärarförmågor blir svåra att utveckla, eftersom miljön är så komplex och svårbemästrad för en novis (jfr Fantilli \& McDougall, 2009; Grossman et al., 2009). Dessutom är det svårt att i tillräcklig utsträckning få tillgång till verkliga klassrum och den coachning som ges av de däri verksamma handledarna är av varierad kvalitet (Cohen et al., 2020). Träningen där studiekamrater agerar elever har som främsta utmaning att det är svårt för andra studenter att på ett realistiskt sätt agera elev (Cohen et al., 2020; Grossman et al., 2009). Simuleringar och simuleringsträning erbjuder ett bra komplement till ovanstående träningsformer. Genom digital teknik är det möjligt att erbjuda lärarstudenter coachad träning i en semivirtuell miljö med simulerade elever (Bautista \& Boone, 20I5; Cohen et al., 2020; Dieker, Rodriguez, Lignuaris/Kraft, Hynes \& Hughes, 2014). Där kan studenterna få vägledd träning i att hantera vanligt förekommande situationer i en trygg miljö som upplevs som autentisk. En fördel är att studenterna kan göra misstag, utan att det riskerar att påverka verkliga elever negativt (O'Callaghan \& Piro, 20I6; Piro \& O'Callaghan, 20I8). Simuleringsträning kan därför fungera som en förberedelse inför den träning som sker på VFU med verkliga elever (Cohen et al., 2020; Dawson \& Lignugaris/Kraft, 2017). Genom specifik och riktad träning i en simulering kan lärarstudenters tilltro till sin egen undervisningsförmåga på så sätt stärkas (Gundel, Piro, Straub \& Smith, 20I9).

Även om forskning om simuleringar och simuleringsträning har genomförts, finns det bara ett fåtal studier som har undersökt effekten av simuleringsträning för lärarstudenter. I en studie av Judge, Bobzien, Maydosz, Gear \& Katsioloudis (2013) undersöks om differentierad återkoppling kan stötta lärarstudenter att tillägna sig strategier för att hantera störande elevbeteende hos virtuella elever. Studenterna delades in i tre grupper som gavs träning i en simulering. Efter träningen fick två grupper återkoppling och en fick det inte, grupp a. Grupp b fick först återkoppling via mail av lärare och därefter av kamrater. Grupp c fick först återkoppling av kamrater, vilket följdes av återkoppling via mail av lärare. Resultatet visar att enbart träning i simuleringen, utan återkoppling, var otillräckligt för att studenter ska tillägna sig den specifika strategin för att hantera störande elevbeteende. Grupp b och c som fick återkoppling utvecklade sin förmåga att hantera störande elevbeteende till följd av återkopplingen. I en studie av Bautista och Boone (2015) undersöks effekten av gruppträning i naturvetenskap med träning i en simulerad miljö i form av TeachLivE. Efter genomförd träning fick alla lärarstudenter individuell återkoppling avseende sina styrkor och svagheter samt instruktioner om hur de kunde arbeta vidare i de efterföljande två sessionerna. Resultatet visade att studenternas tilltro till den egna undervisningsförmågan ökade under den termin de arbetade i den simulerade miljön. Bautista och Boone (2015) menar att utvecklingen beror dels på den personliga återkopplingen, dels på att studenterna gavs chansen att träna på de förmågor som coacherna uppmärksammar. I en studie av Cohen et al. (2020) undersöks hur simuleringsträning i kombination med antingen a) coachning, b) coachning och direkt guidning via öronsnäcka eller c) självreflektion påverkar lärarstudenters förmåga att hantera störande elevbeteenden. I studien framkommer att simuleringsträning i kombination med coachning är det kraftfullaste redskapet för att påverka studenternas ledarskapsförmåga. Cohen et al. (2020) framhåller att det inte räcker att studenterna får träna i en simulerad miljö kopplat till enbart självreflektion. För att studenterna ska utvecklas krävs att träningen är kopplad till ett kursinnehåll och framför allt att varje student får riktad och personlig feedback (Cohen et al., 2020). Baserat på resultat från dessa studier verkar det som om erfarenheter från simuleringsträning med den semivirtuella simuleringen TeachLivE har förutsättningar att vara av betydelse för lärarstudenters undervisningstilltro, framför allt i kombination med återkoppling och coachning. 


\section{Anja Thorsten, Joakim Samuelsson och Marcus Samuelsson}

De studier som beskrivs ovan har alla fokus på att lärarstudenterna ska få möjlighet att träna på att hantera utmanande elevbeteenden. I föreliggande studie fokuseras både på hantering av elevers beteenden och lärarens förmåga att undervisa om matematik på ett sätt som främjar elevers förståelse och lärande. På så sätt skiljer sig denna studien från det som gjorts tidigare.

\section{TEORETISKT RAMVERK}

Denna studie intresserar sig för blivande lärares självtillit, för deras tilltro till sin egen undervisningsförmåga, på engelska Teacher Efficacy Beliefs (TEB) (Tschannen-Moran \& Hoy, 20oI). Detta bygger på Banduras (1997) teori om självtillit. Bandura definierar självtillit som en individs uppfattningar om sin egen förmåga att organisera och utföra uppgifter i syfte att uppnå specifika mål. TEB behandlar således individens uppfattning om sin egen förmåga rörande specifika uppgifter och områden (t.ex. att undervisa i matematik), till skillnad mot näraliggande begrepp som "självuppfattning" och "självkänsla" som inte har ett tydligt fokus på vad som utförs (Tschannen-Moran \& Hoy, 202I). Hoy och Spero (2005) menar att TEB behandlar lärares föreställningar om sin kompetens snarare än deras reella undervisningsförmåga. Det finns dock en tydlig koppling mellan en lärares uppfattning av sin kompetens och vad deras elever presterar i ämnet, vilket gör att mätningen av TEB också kan vara vägvisande för hur läraren undervisar (Caprara et al., 2006).

Bandura (1997) framhåller fyra aspekter som stöd för utveckling av självtillit: iscensättande upplevelser, ställföreträdande erfarenheter, social övertalning samt fysiologiska och emotionella upplevelser. Av dessa anses iscensättande upplevelser vara den mest betydelsefulla aspekten för att utveckla lärares tilltro till sin egen undervisningsförmåga. Bandura (1977) argumenterar för att lyckade iscensatta upplevelser, som till exempel god ordning eller begripliga bedömningar sett ur studenternas perspektiv, leder till en ökad känsla av kompetens. Upprepade misslyckanden däremot, som till exempel oroliga lektioner eller oförmåga att interagera med studenter, sänker känslan av kompetens. Observationer av hur andra lärare utför specifika undervisningsuppgifter ligger till grund för ställföreträdande erfarenheter (Bandura, 1977). Observationer av andra lärares undervisning har potential att bli betydelsefulla, speciellt om de observerade lärarna genomför aktiviteter eller moment som upplevts svåra, och särskilt om de som observerar har begränsad egen undervisningserfarenhet (Labone, 2004). Dessa erfarenheter blir ett underlag i tilltron till den egna undervisningsförmågan när de relateras till egna undervisningserfarenheter och tankar om undervisning (Bandura, 1977). Social övertalning handlar om den återkoppling som ges på en lärares undervisning. Den återkoppling som ges av signifikanta andra är av särskild stor vikt. Signifikanta andra är personer som räknas som betydelsefulla av den som får återkopplingen. Det kan vara mentorer, universitetslärare och handledare, men även föräldrar och elever. Bandura (1997) poängterar att effekten av social övertalning beror på expertisen och trovärdigheten hos den vars åsikt man ska påverkas av. Fysiologiska och emotionella upplevelser med fokus på känslan av lättnad och positiva känslor ligger till grund för självförtroende och förväntan på framgång i framtiden. På liknande sätt kan stressfulla och krävande situationer, beroende på omständigheterna, innehålla värdefull information om den personliga kompetensens möjligheter och begränsningar.

\section{METOD}

För att få svar på forskningsfrågorna valde vi en experimentell design med en interventionsgrupp och en kontrollgrupp. 
Urval

I denna studie har ett antal urval gjorts. Det handlar om vilka som deltagit i studien, vilket test vi använt samt vilken simuleringsmiljö som lärarstudenterna tränat sin undervisningsförmåga i.

\section{Deltagare}

I studien deltog 42 studenter från grundlärarprogrammets utbildning för lärare som utbildas för att undervisa i årskurs 4-6. Studenterna gick sin femte termin på utbildningen när de deltog i studien. De läste en kurs i matematikdidaktik (teorier om undervisning och lärande i matematik) som inleddes med tre veckor teori följt av tre veckor verksamhetsförlagd utbildning och en avslutning med fyra veckor teori. Vi gjorde ett slumpmässigt urval genom att lotta studenterna och på så sätt fördela dem i en interventionsgrupp (2I studenter) och en kontrollgrupp (2I studenter). En grupp (grupp A) startade de tre första veckorna med fokus på matematikdidaktisk teori samt träning i semivirtuell miljö. Den andra gruppen (grupp B) läste också matematikdidaktisk teori, men hade istället för simuleringen seminarier där de diskuterade olika undervisningsupplägg och elevers matematiska lärande. Efter dessa tre veckor hade båda grupperna verksamhetsförlagd utbildning på en skola.

Test

Data om studenternas tilltro till sin egen undervisningsförmåga samlades in via en enkät som studenterna fyllde i före kursen startade (mättillfälle I), före VFU (mättillfälle 2) och efter VFU (mättillfälle 3). Vi hade således tre mätpunkter där vi fokuserade på deras tilltro till sin egen förmåga att leda undervisning i matematik. Enkäten som användes var en översatt version av Sense of Efficacy Scale (24 påståenden) utvecklad av Tschannen-Moran och Hoy (200I) och som också använts av Charalambous, Philippou och Kyriakides (2007). I båda dessa studier användes ett formulär med 24 påståenden. Tschannen-Moran och Hoy (200I), som presenterade en trefaktorslösning för lärare i praktiken, på samma enkät, som de begreppsliggjorde som a) engagemang i lärande, b) antagande om undervisningsstrategier och c) klassrumshantering. Charalambous et al. (2007) presenterade istället en tvåfaktorslösning som de begreppsliggjorde som a) undervisningsförmåga i matematik, b) ledarskapsförmåga i matematikklassrummet. Eftersom tidigare studier inte resulterat i samma faktorstruktur har vi valt att pröva enkäten med en egen explorativ faktoranalys. Vi upptäckte att flera lärarstudenter inte svarade på påståendet som handlade om i vilken utsträckning de kunde stötta familjer som ville hjälpa sina barn att lyckas med matematik. Studenterna menade att de inte hade varit i en sådan situation och därför inte visste hur de skulle svara. Utifrån deras argument togs frågan bort och vi beslöt oss för att använda 23 påståenden där studenterna skulle bedöma sin förmåga att utföra centrala undervisningsuppgifter på en likertskala med nio steg (se Bilaga I).

Semivirtuell miljö

Simuleringen som vi använde är en semivirtuell miljö kallad TeachLivE. Det är en interaktiv, semirealistisk $3 \mathrm{D}$-simulering med virtuella karaktärer, i vårt fall elever, med olika personlighetsdrag (Hayes, Straub, Dieker, Hughes \& Hynes, 20I3). I skolversionen som användes finns fem virtuella elever vars beteende och tal bestäms av en simuleringsspecialist. Specialisterna var i vårt fall två legitimerade lärare med utbildning och erfarenhet av att arbeta med improvisationsteater som utbildats för att styra de virtuella eleverna.

Innehållet i simuleringen skrevs fram som tre scenarier för tre olika tillfällen. Scenarierna fokuserade alla på olika innehåll kopplade till bråk, (a) stambråksrelationer, (b) likvärdiga bråkuttryck och (c) bråk som delar av ett antal. Valet av bråk som matematiskt innehåll baserades på 
att det är ett innehåll som många lärare beskriver som ett av de svåraste innehållen att undervisa om (Newton, 2008; Zhou, Peverly \& Xins, 2006). Scenarierna konstruerades utifrån vad forskning noterat som vanliga missuppfattningar elever kan ha om tal i bråkform (Reynolds \& Muijs, 1999). I relation till varje lektion konstruerades också olika utmaningar om beteenden som skulle utmana studentens ledarskap i klassrummet (Nordenbo, Søgaard Larsen, Tifitkçi, Wendt \& Østergard, 2008; Samuelsson, Arvola, Stenliden \& Nordvall, 20I7). På så sätt tydliggjordes en didaktisk inramning, något som tidigare visat sig vara betydelsefullt vid simuleringsträning (Edman Stålbrandt, 2013; Arvola, Samuelsson, Nordvall \& Ragnemalm, 20I7; Sellberg, 20I8; Cohen et al., 2020).

En annan del av förberedelserna inför undervisningen av de virtuella eleverna handlade om att skingra eventuell oro, stilla nyfikenheten och stimulera lärarstudenterna att delta i studien. Studenterna gavs därför en möjlighet att i förväg bekanta sig med simuleringen och de virtuella eleverna, vilket tidigare studier visat ha stor betydelse för TEB (Bautista \& Boone, 20I5). Vid det tillfället fick lärarstudenterna tillfälle att observera när en forskare interagerade med de virtuella eleverna.

Interventionsgruppen som skulle arbeta i den simulerade miljön delades in i mindre grupper, med tre studenter i varje grupp. Studenterna fick sedan instruktioner om uppgifterna och om innehållet i de tre lektionerna som de skulle planera och genomföra. Instruktionen delades också ut skriftligt till lärarstudenterna i deras kursrum på den lärplattform som lärosätet använde.

\section{Etik}

Vid genomförandet av studien följdes Vetenskapsrådets (2017) etiska råd. Alla studenter som gick kursen informerades om studien och erbjöds möjlighet att delta. Alla utom en gav sitt muntliga samtycke till att delta i studien. Den student som inte gav sitt samtycke ville delta i simuleringsträningen, men fyllde inte i enkäten. All data är anonymiserad och kommer enbart att användas i forskningssyfte.

\section{Genomförande av träning i semivirtuell miljö}

Simuleringsträningen genomfördes i en lokal med en projektor och en whiteboard, se figur I. Inför simuleringen testades video och ljudöverföring.
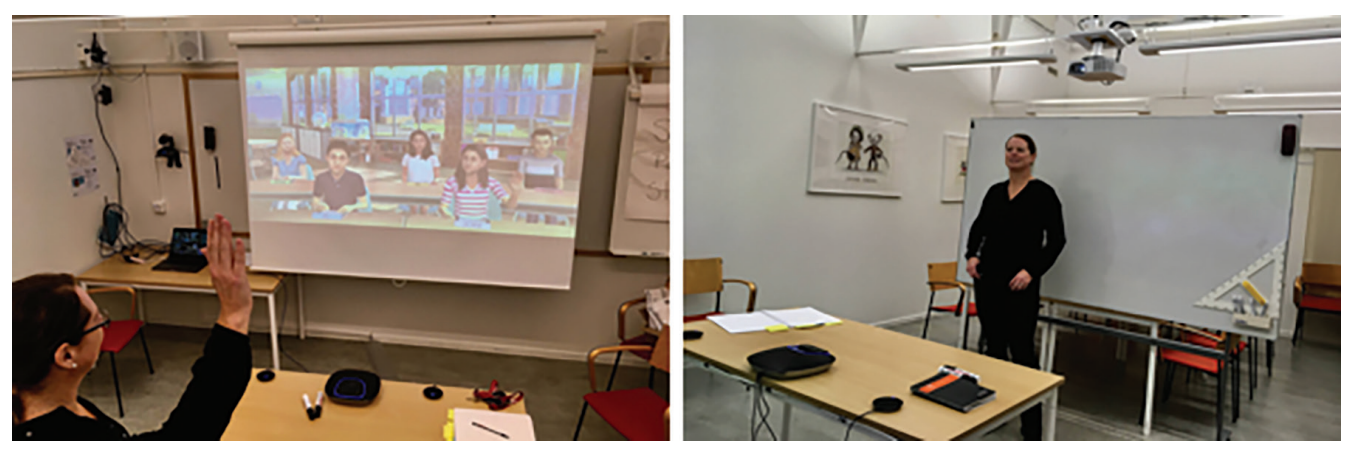

Figur I. En instruktör genomför Tech-Check inför den virtuella praktiken

Studenterna kom till undervisningen i sina grupper vid ett angivet klockslag. De förväntades innan dess ha kommit överens om vem som skulle agera respektive observera vid första, andra och tredje tillfället i simuleringen. Två instruktörer, universitetslärare med specialistkompetens 
i klassrumsledarskap respektive matematikdidaktik mötte upp dem. Instruktörerna förklarade vad studenterna förväntades göra och hur feedbacken skulle gå till, något tidigare forskning lyft fram som viktigt för utveckling av TEB (Larson, Hirsch, McGraw \& Bradshaw, 2019).

De beskrev därefter genomförandet med fokus på mötet med de virtuella eleverna och användandet av tre kommandon, (a) pausa, (b) starta och (c) stoppa, som lärarstudenten som skulle agera i första hand kunde använda sig av. Den första, pausa, kunde studenterna använda när de kände sig osäkra och inte visste hur de skulle hantera en situation eller hur de skulle svara de virtuella eleverna. Pausa innebar att simuleringen stannade, eleverna frös i det de gjorde och sa, för att sedan kunna startas upp från den situationen. När lärarstudenten pausat gavs möjlighet att resonera med de observerande kamraterna om hur situationen kunde förstås och vilka rimliga lösningar som fanns att prova på. Vid behov kunde de också rådfråga de båda instruktörerna. När lärarstudenten bestämt sig för att återigen påbörja interaktionen med de virtuella eleverna användes kommandot starta. Stoppa innebar att simuleringen avslutades.

Instruktörerna informerade om att de tog ansvar för tiden och skulle stoppa simuleringen efter ungefär I 5 minuter. De informerade också om observatörernas roller, att vid ett tillfälle rikta sina observationer mot undervisningen i matematik och vid det andra tillfället rikta sina observationer mot ledarskapet som kamraten visade. Instruktörerna påminde också om att forskning visat att observationerna är lika betydelsefulla som agerandet när lärarstudenter tränat i grupp i simulering (Ely, Alves, Dolenc, Sebold \& Walton 20I8) och att det alltså är betydelsefullt att se när någon annan undervisar (d'Alessio, 2018).

Simuleringen startade genom att den lärarstudent som skulle agera lärare träffade skolans rektor, den virtuella karaktären Bennet. Mötet med Bennet skedde i en virtuell klassrumsmiljö (Judge et al., 20I3; Bautista \& Boone, 20I5) och syftade till att vänja lärarstudenterna vid interaktion med virtuella elever och stärka känslan av fysisk och social närvaro (Ijsselsteijn \& Riva, 2003; van Baren \& IJsselsteijn, 2004). Efter en kort stunds information om att lärarstudenten skulle vikariera för en sjuk lärare och bedriva matematikundervisning enligt lärarens instruktioner, introducerades de fem virtuella eleverna. Ganska omgående började en av de fem eleverna interagera med lärarstudenten om aspekter som klädsel eller frisyr som ett sätt att förstärka känslan av närvaro och realism (Berragan, 20II) och försök till att påverka lärarstudentens känsla av att "vara där", i klassrummet, på riktigt (Lombard \& Ditton, 1997; Dede, 2009).

Vid genomförandet av simuleringen interagerade lärarstudenten med de virtuella eleverna och fick då möta utmaningar rörande både ledarskap och elevers lärande i matematik. Simuleringsspecialisten som styrde de virtuella eleverna använde de förberedda underlagen för scenariet som stöd vid interaktionen med lärarstudenten, men interaktionen var också improviserad. Olika lärarstudenter fick möta delvis olika utmaningar beroende på deras ledar- och undervisningsförmåga samt hur de valde att undervisa om det aktuella innehållet.

När sejouren avslutats gavs återkoppling på den genomförda lektionen. Utformningen för feedbacken var sådan att först fick den som agerat, efter en kort stunds reflektion, svara på frågorna (a) vad som gått bra och (b) vad som kunde gjorts annorlunda. Samma frågor riktades sedan till dem som observerat med fokus på ledarskap och med fokus på matematik. Instruktörerna ställde sedan problematiserande frågor till hela gruppen om sådant som skett på simuleringen rörande både matematikdidaktik och ledarskap. Återkopplingen avslutades genom att instruktörerna lyfte fram det som hade gått bra som ett sätt att utöva ett övertygande inflytande (Bandura, 1997). De två instruktörerna poängterade betydelsen som återkoppling hade för studenternas utveckling i linje med vad tidigare forskning påvisat (Sahin-Taskin, 20I8). 
Lärarstudenterna lämnade därefter den virtuella praktiken. Innan nästa grupp kom till praktiken diskuterade instruktörerna och simuleringsspecialisten den genomförda sejouren. Vid behov justerades inställningar, instruktioner och tillvägagångssätt, för att i möjligaste mån erbjuda bästa möjliga träning i den semivirtuella miljön.

\section{Insamling av data}

Enkäten med frågor om TEB distribuerades vid det första undervisningstillfället, sista undervisningstillfället före VFU samt vid det första undervisningstillfället efter VFU. I direkt anslutning till att studenterna fyllt i enkäten samlades den in av forskarna.

Analys

Analysen av datamaterialet gjordes i två steg. Vi inledde i ett första steg med att göra tre explorativa faktoranalyser för att se om det fanns någon samvariation mellan variablerna i enkäten vid varje mättillfälle. Medelvärde för olika faktorer beräknades genom att multiplicera frågan med faktorladdningen, och därefter beräkna medelvärdet med ingående variabler i respektive faktor.

Därefter genomfördes, i ett andra steg, analyser av studenternas utveckling av tilltron till sin undervisningsförmåga i matematik med hjälp av en ANOVA. Den första analysen fokuserade på utvecklingen under CFU, den andra analysen fokuserade på utvecklingen under VFU och den tredje analysen fokuserade på utvecklingen under både CFU och VFU.

\section{RESULTAT}

Resultatet presenteras i tre delar med fokus på (a) undervisnings- och ledarskapsförmåga (resultat av den explorativa faktoranalysen), (b) utveckling av tilltron till den egna undervisningsförmågan i matematik och (c) utveckling av tilltron till den egna ledarskapsförmågan.

\section{Undervisnings- och ledarskapsförmåga}

Faktoranalyserna som genomfördes av data från tre mättillfällen resulterade i en tvåfaktorlösning vid mätningen före kurs $(64.5 \%$ av variansen förklarades; eigen värde $=$ II.7; 3.I), vid mätningen före VFU (69.2\% av variansen förklarades; eigen värde = I4.3; I.7), och efter VFU (63.3\% av variansen förklarades; eigen värde $=13.3 ; 2.5)$. Faktorerna begreppsliggjordes som (I) Undervisningsförmåga och (II) Ledarskapsförmåga. I tabell I visas dessa faktorer och vilka påståenden som laddat på respektive faktor. För att avgöra antalet faktorer sattes eigen värde I som begränsning. Faktorerna som föll ut av analyserna hade alla ett eigen värde över I.

De påståenden som användes i enkäten laddade på samma faktorstruktur vid alla tre mättillfällen utom i ett fall. Vid tredje mätningen laddade påståendet "I vilken utsträckning kan du hjälpa elever att samarbeta" på ledarskapsförmåga istället för undervisningsförmåga. Vi valde dock att låta det påståendet vara kvar under undervisningsförmåga, dels för att det laddat högt på undervisningsförmåga vid de tidigare mätningarna, dels för att laddningarna på undervisningsförmåga och ledarskap var relativt lika för påståndet vid tredje mätningen.

\section{Utveckling av tilltron till den egna undervisningsförmågan i matematik}

Tilltron till den egna undervisningsförmågan mättes vid tre tillfällen. I tabellen nedan presenteras medelvärde och standardavvikelse för mättillfälle I-3 för båda grupperna.

För att undersöka om det fanns någon skillnad avseende utvecklingen av tilltron till den egna undervisningsförmågan i matematik mellan lärarstudenter som tränat undervisning med virtuella elever under teoriveckorna (grupp A) och de som bara haft teoretiska studier (grupp B) 
Tabell I. Påståenden och laddningar för tre mättillfällen

\begin{tabular}{|c|c|c|c|c|}
\hline \multirow[t]{2}{*}{ Faktor } & Påstående & Mättillfälle & Mättillfälle & Mättillfälle \\
\hline & I vilken utsträckning kan du: & $\mathbf{I}$ & 2 & 3 \\
\hline \multirow[t]{16}{*}{ I } & ge andra förklaringar/exempel när elever inte förstår & .803 & .639 & .664 \\
\hline & använda olika bedömningsstrategier & .602 & .695 & .646 \\
\hline & ställa bra frågor till eleverna & .621 & .622 & .634 \\
\hline & introducera alternativa metoder i klassrummet & .621 & .539 & .576 \\
\hline & svara på frågor från dina elever & .715 & .728 & .718 \\
\hline & skapa en arbetsmiljö som tillgodoser alla elevers behov & .613 & .750 & .645 \\
\hline & bedöma nivån på elevers förståelse av ett innehåll & .623 & .753 & .732 \\
\hline & erbjuda duktiga elever utmanande uppgifter & .749 & .796 & .783 \\
\hline & motivera elever som visar ointresse för matematik & .588 & .622 & .587 \\
\hline & hjälpa elever att samarbeta & .713 & .646 & .496 \\
\hline & hjälpa elever att uppskatta och se värdet i att lära sig matematik & .772 & .749 & .749 \\
\hline & elever att tro att de kan prestera bra i matematik & $.68 \mathrm{I}$ & .604 & .586 \\
\hline & hjälpa en elev med stora svårigheter i matematik & .595 & .739 & .698 \\
\hline & hjälpa en elev att tänka kreativt & .766 & $.69 \mathrm{I}$ & .666 \\
\hline & hjälpa en elev att tänka kritiskt & .601 & $.8 \mathrm{I} 4$ & $.75 \mathrm{I}$ \\
\hline & förändra dina lektioner till en lagom nivå för alla elever & .529 & .658 & .675 \\
\hline \multirow[t]{7}{*}{ II } & skapa rutiner som får arbetet i klassrummet att fungera smidigt & .530 & .673 & .662 \\
\hline & kommunicera dina förväntningar på elevers beteende i klassrummet & .626 & .743 & $.7 \mathrm{II}$ \\
\hline & hantera ett fåtal störande elever från att förstöra hela lektionen & .775 & .796 & $.79 \mathrm{I}$ \\
\hline & hantera störande beteenden i klassrummet & .877 & .887 & .876 \\
\hline & lugna elever som avbryter och är högljudda & $.82 \mathrm{I}$ & .886 & .878 \\
\hline & få elever att följa klassrumsregler & .738 & .737 & .727 \\
\hline & hantera trotsiga elever & .732 & .796 & .754 \\
\hline
\end{tabular}

Tabell 2. Medelvärde och standardavvikelse relaterat till tilltro till den egna undervisningsförmågan $i$ matematik

\begin{tabular}{|c|c|c|c|c|}
\hline \multirow[b]{2}{*}{ Mättillfälle } & \multicolumn{2}{|c|}{ Grupp A } & \multicolumn{2}{|c|}{ Grupp B } \\
\hline & $\mathbf{M}$ & SD & $\mathbf{M}$ & SD \\
\hline I & 5.14 & .90 & 4.85 & I.O7 \\
\hline 2 & 6.56 & .89 & 5.15 & I.I2 \\
\hline 3 & 7.26 & .86 & 5.96 & I. 23 \\
\hline
\end{tabular}

använde vi en ANOVA där faktorn undervisningsförmåga användes som beroende variabel. Resultatet av analysen visade en signifikant interaktionseffekt mellan grupp och tid (I-2), $F(\mathrm{I}, 40)=\mathrm{I} 6,24, p<\mathrm{0}, \mathrm{OOI}, \eta=.289^{\mathrm{I}}$. Det fanns också en huvudeffekt av tid, $F(\mathrm{I}, 40)=37,7$ $p<0,001, \eta=.49$, och en huvudeffekt av grupp, $F(\mathrm{I}, 40)=\mathrm{II}, 37, p=0,002, \eta=0,22$. En andra ANOVA genomfördes för att studera utvecklingen på de båda grupperna under VFU.

1 F-värdet som presenteras illustrerar skillnaden mellan grupperna. En större skillnad mellan gruppernas testvärden ger ett större F-värde, vilket är en indikator på om det finns en statistisk skillnad mellan grupperna. I relation till varje test presenteras ett p-värde vilket illustrerar sannolikheten för att det finns skillnad mellan grupperna. Ett p-värde $<.05$ anses visa att det finns en statistiskt signifikant skillnad. Eta $(\eta)$ beräknades för alla signifikanta skillnader. Värdet illustrerar vilken effekt interventionen har haft, dvs. hur bra interventionen fungerat. Ett värde över 0.01-0.06 räknas som låg effekt, mellan .06 och 0.14 som medeleffekt och $>0.14$ som hög effekt. 
Resultatet visade ingen interaktionseffekt mellan grupp och tid (2-3), $F(\mathrm{I}, 40)=.195, p>.05, \eta$ $=.005$, vilket indikerar att båda grupperna utvecklades lika mellan mättillfällena två och tre, det vill säga när båda grupperna genomförde sin VFU. Det fanns huvudeffekter av tid, $F(\mathrm{I}, 40)=$ 35,II, $p<$ o, OOI, $\eta=.47$, och huvudeffekter av grupp, $F(\mathrm{I}, 40)=25$, OI, $p<0$,ooI, $\eta=.39$.

Analysen visade också att studenter som övat undervisning med virtuella elever under teoriveckorna på CFU och haft VFU hade utvecklat tilltron till sin undervisningsförmåga i matematik signifikant mer än studenter som bara läst teori och därefter haft verksamhetsförlagd utbildning. Resultatet av analysen visade en interaktionseffekt mellan grupp och tid, (I-3), $F(2,40)=6,54, p<$. oI, $\eta=$. I4, och en huvudeffekt av tid, $F(2,40)=66,75, p<0,001, \eta=0,63$, och en huvudeffekt av grupp, $F(\mathrm{I}, 40)=3 \mathrm{I}, 56, p<0,00 \mathrm{I}, \eta=.30$.

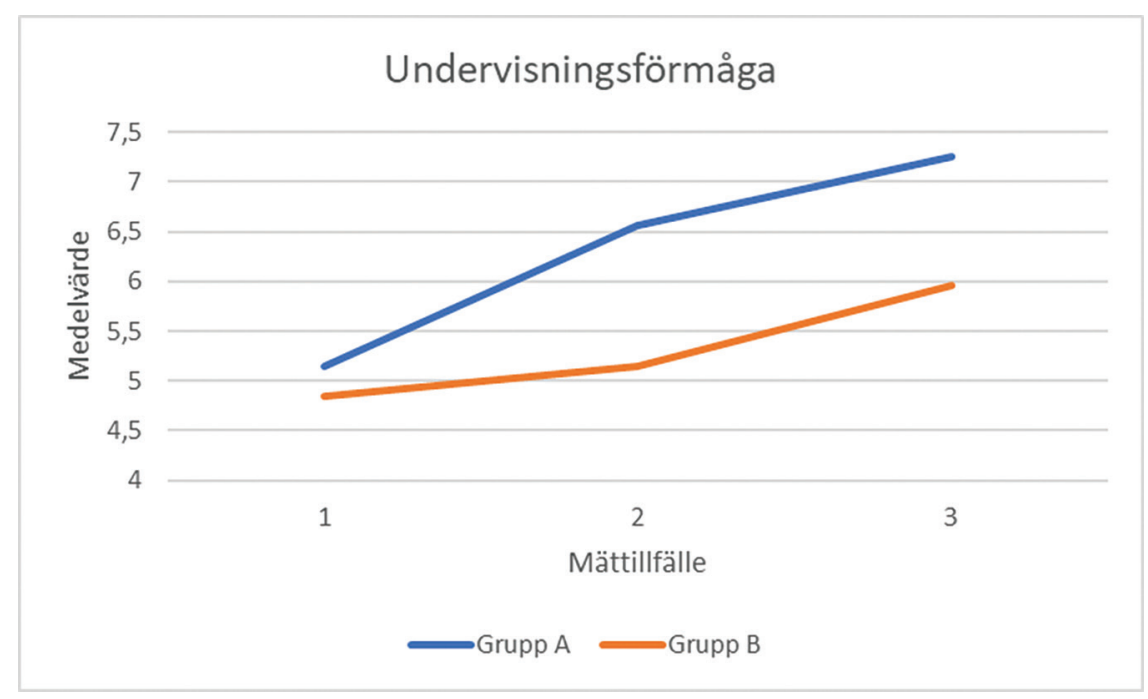

Figur 2. Utveckling av tilltro till undervisningsförmåga i matematik

\section{Utveckling av tilltron till den egna ledarskapsförmågan}

Tilltron till den egna ledarskapsförmågan mättes, liksom tilltron till den egna undervisningsförmågan, vid tre tillfällen. I tabellen nedan presenteras medelvärde och standardavvikelse för mättillfälle I-3 för båda grupperna.

Tabell 3. Medelvärde och standardavvikelse relaterat till tilltro till den egna ledarskapsförmågan

\begin{tabular}{cccccc}
\hline & \multicolumn{3}{c}{ Grupp A } & & \multicolumn{3}{c}{ Grupp B } \\
\cline { 2 - 3 } \cline { 5 - 6 } Mättillfälle & M & SD & & M & SD \\
\hline I & 5.58 & I.I9 & & 5.19 & I.I2 \\
2 & 7.16 & 1.08 & & 5.29 & I.16 \\
3 & 7.44 & 1.07 & & 5.97 & I.17 \\
\hline
\end{tabular}

För att undersöka om det fanns någon skillnad avseende utvecklingen av tilltron till den egna ledarskapsförmågan mellan lärarstudenter som tränat undervisning med virtuella elever under teoriveckorna och de som bara haft teoretiska studier använde vi en ANOVA där faktorn ledarskapsförmåga användes som beroende variabel. Analysen visade en signifikant interaktionseffekt 
mellan grupp och tid (I-2), $F(\mathrm{I}, 40)=\mathrm{II}, 56, p<0,00 \mathrm{I}, \eta=.3 \mathrm{I}$. Det fanns också en huvudeffekt av tiden, $F(\mathrm{I}, 40)=\mathrm{I} 4,7 p<0$,00I, $\eta=.36$, och en huvudeffekt av gruppen, $F(\mathrm{I}, 40)=\mathrm{I} 3,77$, $p=0, \mathrm{OOI}, \eta=0,26$. Resultatet visar att tilltron till den egna ledarskapsförmågan utvecklades signifikant mer i grupp A under teoriveckorna.

Utvecklingen avseende tilltro till den egna ledarskapsförmågan under VFU analyserades med ytterligare en ANOVA. Analysen visade ingen interaktionseffekt mellan grupp och tid (2-3), $F(\mathrm{I}, 40)=\mathrm{I}, 93, p>.05, \eta=.046$. Detta resultat indikerar att båda grupperna utvecklades lika med avseende på förmågan att leda eleverna i klassrummet. Resultatet av analysen visade även en huvudeffekt av tid, $F(\mathrm{I}, 40)=$ I0,83, $p=0,002, \eta=.2 \mathrm{I}$, och en huvudeffekt av grupp, $F(\mathrm{I}, 40)=$ 28,87, $p<$ o,oOI, $\eta=0,4 \mathrm{I}$.

Avslutningsvis gjordes en tredje ANOVA för att undersöka utvecklingen av tilltron till den egna ledarskapsförmågan mellan mättillfälle ett och tre. Resultatet visade en signifikanta interaktionseffekter mellan grupp och tid (I-3), $F(2,40)=9,47, p<$. oI, $\eta=$. I9, en huvudeffekter av tid, $F(2,40)=28,78, p<0,00 \mathrm{I}, \eta=.42$, och en huvudeffekt av grupp, $F(\mathrm{I}, 40)=\mathrm{I} 8,98, p<0$, o०I, $\eta=.32$. Det betyder att de studenter som tränat på undervisning med virtuella elever under teoriveckorna och haft VFU hade utvecklat tilltron till sin egen ledarskapsförmåga signifikant mer än studenter som bara läst teori på CFU och därefter haft VFU.

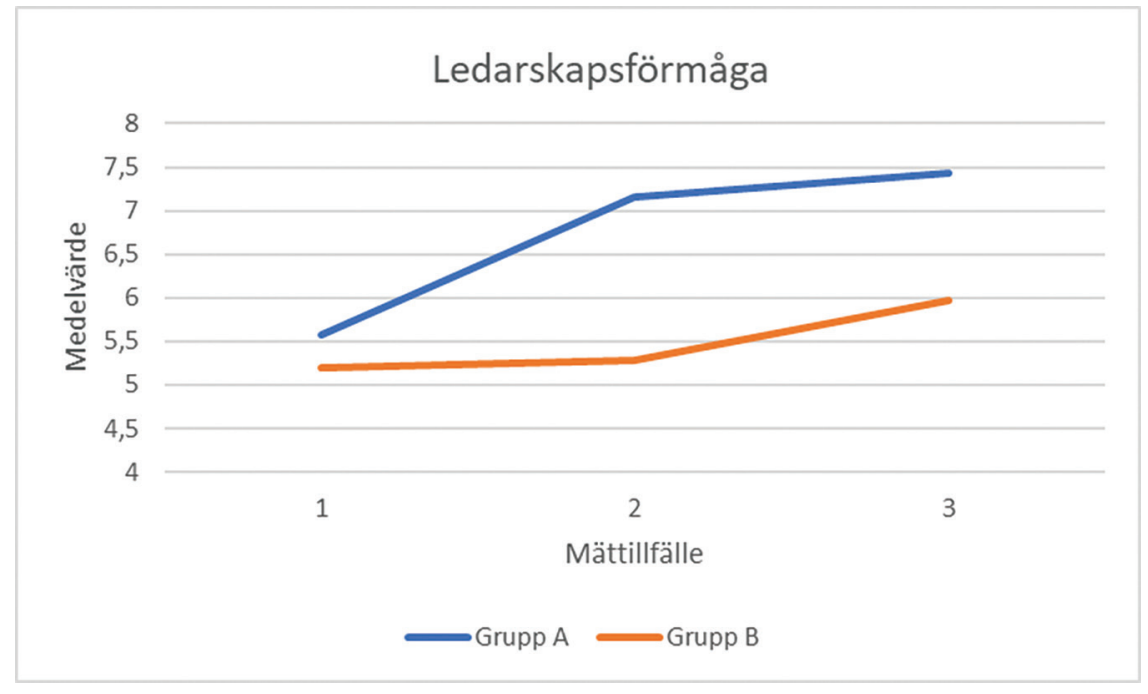

Figur 3. Intergruppsjämförelse av utveckling av förmågan att leda klassrummet

Sammanfattningsvis visar resultaten från den här studien att begränsat antal och relativt lite träning av undervisning med virtuella elever hjälpte lärarstudenter att utveckla tilltron till såväl sin egen undervisningsförmåga i matematik som sin ledarskapsförmåga.

\section{DISKUSSION}

Föreliggande studie bidrar med kunskap om betydelsen av att kombinera teoretiska och praktiska moment i yrkesutbildning inom högre utbildning (Anthony et al., 2015; Grossman et al., 2009; McDonald et al., 20I3). Våra resultat visar att lärarstudenter som får coachad simuleringsträning inom ramen för en matematikdidaktisk kurs ökar tilltron till sin egen förmåga att 
leda undervisningen i matematik signifikant mer än studenter som enbart deltar i de teoretiska delarna i matematikdidaktikkursen. Det resultatet är i linje med Bautista och Boone (2015) som visat att tilltron till den egna undervisningsförmågan ökar när studenterna får coachad simuleringsträning. Tilltron till den egna undervisningsförmågan utvecklas sedan under VFU:n på ett liknande sätt för båda grupperna. Det innebär att gruppen som fått coachad simuleringsträning före VFU:n har en signifikant högre tilltro till sin undervisningsförmåga även efter VFU:n jämfört med gruppen som enbart deltagit i de teoretiska delarna av matematikdidaktikkursen. Träning i den simulerade miljön har förstärkt den träning som ges på VFU vilket även Cohen et al. (2020) och Dieker et al. (2014) visat. Flera av de tidigare studierna på området (jfr Judge, et al., 20I3; Gundel et al., 2019) har endast fokuserat på att utveckla studenternas tilltro att leda eleverna i klassrummet och påverka deras beteende. Våra resultat visar att lärarstudenter kan utveckla sin tilltro till både didaktiska kompetenser och ledarskapskompetenser genom att träna undervisning av virtuella elever. En förklaring till att tilltron till såväl undervisningsförmåga som ledarskapsförmåga utvecklas kan vara att $\mathrm{i}$ vår simulering är matematiken $\mathrm{i}$ förgrunden, samtidigt som studenterna tränar på att leda undervisningen och hantera elever som stör ordningen eller som på olika sätt förlorar uppgiftsfokus. Eftersom Caprara et al. (2006) påtalar att det finns en koppling mellan den egna uppfattningen av undervisningskompetensen och elevernas lärande, går det att anta att när studenterna ökar sin tilltro till sin förmåga att leda matematikundervisning så blir de också skickligare i att undervisa. Det är dock bara ett antagande och skulle i framtida studier behöva undersökas närmare.

En slutsats från studiens resultat är att studenterna behöver få praktisk träning även på den campusförlagda utbildningen. Det innebär dock inte att vi förordar vilken träning som helst. Det finns flera förklaringar till att studenterna utvecklar tilltron till sin egen undervisningsförmåga och ledarskap i matematikklassrummet via den simuleringsträning de deltog i. En första förklaring kan vara att träningen sker i en trygg, avskalad miljö (jfr Grossman et al., 2009; Cohen et al., 2020), men att kärnan i yrket och dess grundläggande komplexitet, en känsla av realism och fysisk närvaro finns kvar (Ijsselsteijn \& Riva, 2003; van Baren \& IJsselsteijn, 2004; Berragan, 20II). Med stöd av de framtagna scenarierna tydliggjordes den didaktiska inramning vilket tidigare studier visat har betydelse för utfallet av simuleringsträningen (Edman Stålbrandt, 2013; Samuelsson et al., 2017; Sellberg, 2018). En andra förklaring kan vara att träningen i sig gör att studenterna får det Bandura (1997) benämner iscensättande upplevelser. Dessa erfarenheter gör att de inte bara kan prata om undervisning utan också kan agera och vara $i$ undervisning. Det handlar om att få träna på att undervisa och att få erfarenheten i kroppen. Samtidigt stöttas lärandet av coacherna som kan ge riktad, direkt och personlig feedback, som dessutom är grundad i relevanta teoretiska sammanhang. Coacherna fungerar som en slags social övertalning enligt Banduras (1997) terminologi. Den teoretiska kunskapen från kursen kopplas samman med den praktiska kunskapen (Grossman et al., 2009), vilket Cohen et al. (2020) menar är viktigt att studenterna får stöd med i utvecklandet av sin undervisningsförmåga. Cohen et al. (2020) framhåller att självreflektioner inte räcker, det är inte ens ett särskilt kraftfullt redskap. Därför är det nödvändigt att ha coacher. För att studenten ska ta till sig av coachernas feedback behöver de själva uppleva coacherna som kompetenta och viktiga personer (Bandura, 1997). Den coachade simuleringsträningen möjliggör därmed att yrkeskunnandets handlingsorienterade sida och dess analysorienterade sida sammankopplas. En tredje förklaring kan vara att kombinationen av simulering och coachning även ger viktiga erfarenheter för de studenter som observerar simuleringsträningen (d'Alessio, 20I8). De kan göra ställföreträdande upplevelser (Bandura, 1997) och på så sätt utvidga sin arsenal av redskap i undervisningen. Eftersom dessa 
studenter dessutom har varit med och planerat den observerade sessionen, kan det antas att de finner det särskilt intressant att se hur det fungerar. De får då ett personligt engagemang även när de själva inte agerar som lärare. Den personliga fysiologiska och emotionella upplevelsen beskriver Bandura (1997) som viktig, oavsett om studenten gör iscensättande eller ställföreträdande upplevelser eftersom starkare känslor gör att vi påverkas mer av våra upplevelser och erfarenheter.

Föreliggande studie genomfördes på ett lärarprogram. Oavsett det kan det inte uteslutas att simuleringsträning kan vara funktionell även på andra yrkesutbildningar där studenterna med hjälp av coachad träning får möjlighet att utveckla yrkesspecifika förmågor.

\section{FÖRFATTARPRESENTATION}

Anja Thorsten är lektor i pedagogik vid Linköpings universitet. Hon forskar om didaktiskt ledarskap, virtuell praktik, professionsutveckling och om relationen undervisning - lärande. Hon arbetar på lärarutbildningen bland annat i kurser om skolutveckling, didaktik och ledarskap. Hon är också simuleringsexpert i simuleringen TeachLivE.

Joakim Samuelsson är professor i pedagogik med inriktning mot matematikdidaktik vid Linköpings universitet. Hans forskning handlar om undervisning och lärande i matematik på alla nivåer i utbildningssystemet samt hur lärares professionella kunskap med fokus på matematikundervisning kan utvecklas.

Marcus Samuelsson är biträdande professor i pedagogik vid Linköpings universitet. Där är han också verksam som forskningsledare för forskargruppen FoDiL som ägnar sig åt forskning om didaktiskt ledarskap. Detta fenomen, kopplat till simuleringsträning, riktas hans forskning och stora delar av hans undervisning åt. Han är en erfaren instruktör i simuleringen TeachLivE.

\section{REFERENSER}

Anthony, G., Hunter, J. \& Hunter, R. (2015). Prospective teachers development of adaptive expertise. Teaching and Teacher Education, 49, I08-II7.

Arvola, M., Samuelsson, M., Nordvall, M. \& Ragnemalm, E. (2018). Simulated Provocations: A Hypermedia Radio Theatre for Reflection on Classroom Management. Simulation \& Gaming, 49, 98-II4.

Bandura, A. (1977). Self-efficacy: Towards a unifying theory of behavioral change. Psychological Review, 84(2), I9I-2I5.

Bandura, A. (1997). Self-efficacy: The exercise of control. New York: Freeman.

Bautista, N. U. \& Boone, W. J. (20I5). Exploring the impact of TeachMe ${ }^{\mathrm{TM}}$ lab virtual classroom teaching simulation on early childhood education majors' self-efficacy beliefs. Journal of Science Teacher Education, 26(3), 237-262.

Berragan, L. (20II). Simulation: An effective pedagogical approach for nursing? Nurse Education Today, $3 I(7), 660-663$.

Caprara, G. V., Barbaranelli, C., Steca, P. \& Malone, P. S. (2006). Teachers's self-efficacy beliefs as determinants of job satisfaction and students' academic achievement: A study at the school level. Journal of School Psychology, 44(6), 473-490.

Charalambous, C. Y., Philippou, G. N. \& Kyriakides, L. (2007). Tracing the development of preservice teachers' efficacy beliefs in teaching mathematics during fieldwork. Educ Stud Math, 67(2), I25-I42.

Cohen, J., Wong, V., Krishnamachari, A. \& Berlin, R. (2020). Teacher Coaching in a Simulated Environment. Educational Evaluation and Policy Analysis, 20(10), I-24.

d'Alessio, M. A. (2018). The Effect of Microteaching on Science Teaching Self-Efficacy Beliefs in Preservice Elementary Teacher. Journal of Science Teacher Education, 29(6), 44I-467. 


\section{Anja Thorsten, Joakim Samuelsson och Marcus Samuelsson}

Dawson, M. R. \& Lignugaris/Kraft, B. (20I7). Meaningful Practice: Generalizing Foundation Teaching Skills. From TLE TeachLivE ${ }^{\mathrm{TM}}$ to the Classroom. Teacher Education and Special Education, 40(I), 26-50.

Dede, C. (2009). Immersive interfaces for engagement and learning. Science, 323(5910), 66-69.

Dieker, L. A., Rodriguez, J. A., Lignugaris/Kraft, B., Hynes, M. C. \& Hughes, C. E. (20I4). The Potential of Simulated Environments in Teacher Education: Current and Future Possibilities. Teacher Education and Special Education, 37(I), 2I-33.

Edman Stålbrandt, E. (2013). Simulerade skoldilemman - redskap för utveckling av reflektionsförmåga? Åbo: Åbo Akademi.

Ely, E., Alves, K. D., Dolenc, N. R., Sebolt, S. \& Walton, E. A. (2018). Classroom Simulation to Prepare Teachers to Use Evidence-Based Comprehension Practices. Journal of Digital Learning in Teacher Education, 34(2), 7I-87.

Fantilli, R. D. \& McDougall, D. E. (2009). A Study of Novice Teachers: Challenges and Supports in the First Years. Teaching and Teacher Education, 25(6), 8I4-825.

Granström, K. (2007). Ledarskap i klassrummet. I: K. Granström (Red.), Forskning om lärares arbete i klassrummet (s. 13-32). Stockholm: Myndigheten för skolutveckling.

Grossman, P. (2005). Research on pedagogical approaches in teacher education. I M. Cochran-Smith \& K. Zeichner (Red.), Review of research in teacher education (pp. 425-476). American Educational Research Association.

Grossman, P., Hammerness, K. \& McDonald, M. (2009) Redefining teaching, re-imagining teacher education, Teachers and Teaching, I5(2), 273-289.

Gundel, E., Piro, J. S., Straub, C. \& Smith, K. (2019). Self-Efficacy in Mixed Reality Simulations: Implications for Preservice Teacher Education, The Teacher Educator, 54(3), 244-269.

Hattie, J. (2009). Visible learning: A synthesis of $800+$ meta-analyses on achievement. London: Routledge.

Hayes, A. T., Straub, C. L., Dieker, L. A., Hughes, C. E. \& Hynes, M. C. (2013). Ludic Learning: Exploration of TLE TeachLivE ${ }^{\mathrm{TM}}$ and Effective Teacher Training. International Journal of Gaming and Computer-Mediated Simulations, 5(4I), 20-33.

Hoy, W. A. \& Burke Spero, R. (2005). Changes in Teacher Efficacy during the EarlyYears of Teaching: A Comparison of Four Measures. Teaching and Teacher Education, 2I, 343-356.

Ijsselsteijn, W. A. \& Riva, G. (2003). Being There: The Experience of Presence in Mediated Environments. I G. Riva, F. Davide \& W. A. IJsselsteijn. Being There: Concepts, Effects and Measurements of User Presence in Synthetic Environments. Amsterdam: IOS Press.

Judge, S., Bobzien, J., Maydosz, A., Gear, S. \& Katsioloudis, P. (2013). The use of visual-based simulated environments in teacher preparation. Journal of Education and Training Studies, I(I), 88-97.

Labone, E. (2004). Teacher efficacy: Maturing the construct through research in alternative paradigms. Teaching and Teacher Education, 20(4), 34I-359.

Larson, K. E., Hirsch, S. E., McGraw, J. P. \& Bradshaw, C. P. (20I9). Preparing Preservice Teachers to Manage Behavior Problems in the Classroom: The Feasibility and Acceptability of Using a Mixed-Reality Simulator. Journal of Special Education Technology, 35(2), I-I3.

Lindqvist, H., Weurlander, M., Wernerson, A. \& Thornberg, R. (2019). Conflicts viewed through the micro-political lens: Beginning teachers' coping with emotionally challenging situations. Research Papers in Education.

Lombard, M. \& Ditton, T. B. (1997). At the Heart of It All: The Concept of Presence. Journal of Computer-mediated Communication, $3(2)$.

McDonald, M., Kazemi, E. \& Schneider Kavanagh, S. (2013). Core Practices and Pedagogies of Teacher Education: A Call for a Common Language and Collective Activity. Journal of Teacher Education, $64(5), 378-386$.

Newton, K. J. (2008). An extensive analysis of preservice elementary teachers' knowledge of fractions. American Educational Research Journal, 45(4), I080-IIIO.

Nordenbo, S.-E., Søgaard Larsen, M., Tifitkçi, N., Wendt, R. E. \& Østergard, S. (2008). Larerkompetencer og elevers laring i forskole og skole. Copenhagen: Dansk Clearinghouse for Uddanelseforskning. 
O'Callaghan, C. \& Piro, J. (2016). Virtual Simulations in a Practice Based Teacher Education. The Field Experience Journal, $17(\mathrm{I})$, 94-II8.

Piro, J. \& O'Callaghan, C. (2018). Journeying Towards the Profession: Exploring Liminal Learning within Mixed Reality Simulations. Action in Teacher Education, 4I(I), 79-95.

Reynolds, D. \& Muijs, D. (1999). The effective teaching of mathematics: A review of research. School Leadership \& Management, Ig(3), 273-288.

Roofe, C. C. \& Miller, P. (2013). "Miss, I am not being fully prepared”: Student-teachers' concerns about their preparation at a teacher training institution in Jamaica. Australian Journal of Teacher Education, $38(5), \mathrm{I}-\mathrm{I} 3$.

Sahin-Taskin, C. (2018). Effects of active learning environments supported with self- and peer assessment on pre-service teachers' pedagogical and self-efficacy beliefs. Asia-Pacific Journal of Teacher Education, 46(5), 42I-440.

Samuelsson, M., Arvola, M., Stenliden, L. \& Nordvall, M. (2017). Simuleringsbaserad undervisning som ett kompletterande inslag i lärarutbildningen vid Linköpings universitet. Linköping: Linköpings universitet, Didacticum.

Sellberg, C. (2018). Training to become a master mariner in a simulator-based environment: The instructors' contribution to professional learning. Göteborg: Göteborgs universitet.

Tschannen-Moran, M. \& Hoy, A. W. (200I). Teacher efficacy: Capturing an elusive construct. Teaching and Teacher Education, I7(7), 783-805.

Uljens, M. (Red.) (2004). Didaktik: teori, reflektion och praktik. Lund: Studentlitteratur.

van Baren, J. \& IJsselsteijn, W. (2004). Measuring Presence: A Guide to Current Measurement Approaches. Eindhoven University of Technology.

Vetenskapsrådet. (2017). God forskningssed. Stockholm: Vetenskapsrådet.

Westbury, I., Hansén, S. E., Kansanen, P. \& Björkvist, O. (2005). Teacher education for research-based practice in expanded roles: Finland's experience. Scandinavian Journal of Educational Research, 49(5), $475-485$.

You, S. \& Conley, S. (2015). Workplace predictors of secondary school teachers' intention to leave: An exploration of career stages. Educational Management Administration \& Leadership, 43(4), 56I-58I.

Zhou, Z., Peverly, S. T. \& Xin, T. (2006). Knowing and teaching fractions: A cross-cultural study of American and Chinese mathematics teachers. Contemporary Educational Psychology, 3I, 438-457. 


\section{Anja Thorsten, Joakim Samuelsson och Marcus Samuelsson}

\section{BILAGA I}

I. I vilken utsträckning kan du ge andra förklaringar/exempel när elever inte förstår

2. Hur väl kan du skapa rutiner som får arbetet i klassrummet att fungera smidigt

3. I vilken utsträckning kan du använda olika bedömningsstrategier

4. Hur väl kan du kommunicera dina förväntningar på elevers beteende i klassrummet

5. I vilken utsträckning kan du ställa bra frågor till eleverna

6. Hur väl kan du hantera trotsiga elever

7. I vilken utsträckning kan du introducera alternativa metoder i klassrummet

8. I vilken utsträckning kan du hantera störande beteenden i klassrummet

9. I vilken utsträckning kan du svara på frågor från dina elever

IO. I vilken utsträckning kan du lugna elever som avbryter och är högljudda

II. I vilken utsträckning kan du förändra dina lektioner till en lagom nivå för alla elever

I2. I vilken utsträckning kan du få elever att följa klassrumsregler

I3. I vilken utsträckning kan du bedöma nivån på elevers förståelse av ett innehåll

I4. Hur väl kan du hantera ett fåtal störande elever från att förstöra hela lektionen

15. I vilken utsträckning kan du erbjuda duktiga elever utmanande uppgifter

I6. I vilken utsträckning kan du motivera elever som visar ointresse för matematik

I7. I vilken utsträckning kan du hjälpa elever att samarbeta

I8. I vilken utsträckning kan du hjälpa elever att uppskatta och se värdet i att lära sig matematik

I9. I vilken utsträckning kan du påverka elever att tro att de kan prestera bra i matematik

20. I vilken utsträckning kan du hjälpa en elev med stora svårigheter i matematik

2I. I vilken utsträckning kan du hjälpa en elev att tänka kreativt

22. I vilken utsträckning kan du hjälpa en elev att tänka kritiskt

23. I vilken utsträckning kan du skapa en arbetsmiljö som tillgodoser alla elevers behov 